\title{
Effect of MgO MicroParticles on Characteristics of Microarc Oxidation Coatings Fabricated on Pure Titanium
}

\author{
Ping Wang*, YouTao Xiao, ZhenHui Zhou, Jun Pu, WenJie Cao, Zeyu Gong, Jie Hu \\ School of Materials Science and Engineering, Southwest Petroleum University, Chengdu, China \\ *E-mail: 818wp@163.com
}

doi: $10.20964 / 2019.01 .16$

Received: 13 June 2018 / Accepted: 18 October 2018 / Published: 30 November 2018

\begin{abstract}
Microarc oxidation coatings were successfully fabricated on TA2 pure titanium by the microarc oxidation method in electrolyte solutions using different concentrations of $\mathrm{MgO}$ microparticles $(0 \sim 4$ $\mathrm{g} / \mathrm{L}$ ). The effect of $\mathrm{MgO}$ microparticles on the surface morphologies, composition and properties of the MAO coatings was investigated. It was observed that the concentration of $\mathrm{MgO}$ microparticles had a significant impact on the characteristics of the MAO coatings. With increasing concentrations of $\mathrm{MgO}$ microparticles, the oxidation voltage increased, and the microhardness, thickness and interface adhesion of the MAO coatings increased. The surface roughness of the MAO coatings gradually increased. MAO coatings are mainly composed of $\mathrm{SiO}_{2}$, rutile, anatase, $\mathrm{MgTiO}_{3}$ and $\mathrm{MgO}$. The corrosion rates exhibited a trend from decreasing to increasing rates. The samples exhibited good thermal shock resistance properties.
\end{abstract}

Keywords: Microarc oxidation; $\mathrm{MgO}$ microparticles; Pure titanium; Characteristics

\section{FULL TEXT}

(C) 2019 The Authors. Published by ESG (www.electrochemsci.org ). This article is an open access article distributed under the terms and conditions of the Creative Commons Attribution license (http://creativecommons.org/licenses/by/4.0/). 